\title{
Phakomatosis pigmentokeratotica
}

\author{
INSERM
}

\section{Source}

INSERM. (1999). Orphanet: an online rare disease and orphan drug data base.

Phakomatosis pigmentokeratotica. ORPHA:2874

Phakomatosis pigmentokeratotica (PPK) is a very rare epidermal nevus disorder characterized by the association of speckled lentiginous nevi with epidermal sebaceous nevi, and extracutaneous anomalies. 